Serum amylase levels in patients in this type of coma without clinical evidence of pancreatitis have seldom been reported and have usually been normal. The level reported in the present patient was raised but not enough to be diagnostic of acute pancreatitis. Although acute renal failure does produce raised levels it is unlikely to have been the cause here, because the amylase level fell to normal long before the blood urea began to fall.

The intravascular haemolysis lasted for a few days only and subsequent screening for abnormal haemolytic mechanisms, such as cold agglutinins, Coombs' test, osmotic fragility and haemoglobinopathy, was negative. The fact that the platelet count never fell below normal made microangiopathic haemolysis unlikely.

A more likely cause of the haemolysis became evident when considering the intravenous fluid used. In the first $6 \mathrm{hr}$ the patient received 11 of $0.9 \%$ and 21 of $0.18 \%$ saline. This was followed by a further 41 of $0.18 \%$ saline in the next $24 \mathrm{hr}$. The large volume given was needed and the hypotonic solution used as it appeared appropriate. However, because of the rapidity of infusion this could have made the area around the tip of the cannula hypotonic and caused haemolysis. One-fifth 'normal', or $0.18 \%$, saline has been used for correcting dehydration in babies for a long time, but is seldom used now as haemolysis sometimes occurred.

We have no definite proof that the hypotonic saline infusion caused the haemolysis in our patient, but it seems likely. If large volumes of fluid are needed rapidly intravenously, $0.45 \%$ saline or infusions of $0.9 \%$ saline and $5 \%$ dextrose alternately are suitable.

\section{Acknowledgment}

We are grateful to Dr J. E. G. Pearson for permission to make this report.

\section{References}

Clements, R.S., Prockop, L.D. \& Winegrad, A.I. (1968) Acute cerebral oedema during treat ment of hyperglycaemia. Lancet, ii, 384.

Halmos, P.B., Nelson, J.K. \& Lowry, R.C. (1966) Hyperosmolar non-ketoacidotic coma in diabetes. Lancet, i, 675.

Maccario, M. \& Messis, C.P. (1969) Cerebral oedema complicating treated non-ketotic hyperglycaemia. Lancet, ii, 352.

Postgraduate Medical Journal (1971) Supplement, June, pp. 371.

ViniK, A., Seftel, H. \& Joffe, B.I. (1970) Metabolic findings in hyperosmolar non-ketotic diabetic stupor. Lancet, ii, 797.

\title{
Villous adenoma in a blind duodenal loop
}

\author{
P. E. JONES* \\ M.B., M.R.C.P.
}

\author{
J. F. ClegG \\ M.A., M.B., Ch.B., F.R.C.S.
}

\section{Manchester Northern Hospital, Manchester 7PJ}

\section{Summary}

A case of a villous adenoma in a blind duodenal loop is described. The difficulties in diagnosis are illustrated and the literature on duodenal villous tumours is reviewed.

\section{Introduction}

Since the first report in 1861 by Holmes, it has become apparent that villous adenomata are rare in the gastrointestinal tract, apart from the colon and rectum. In a review of ninety-three instances of villous tumours in parts of the intestinal tract other than colon and rectum (Bremer, Battaile \& Bulle, 1968), eighty-two were in the stomach, five were in the jejunum and ileum and only six in the duodenum.

\footnotetext{
* Present address: Whittington Hospital, Archway Wing, London, N.19.
}

A further five cases of duodenal villous tumours have been reported (Boyer \& Hellfrich, 1966; Dwyer \& O'Brien, 1970; Hancock, 1970; Makkar, Taek Song \& Cogbill, 1969; Schorsch \& Gutierrez, 1965), none have been reported in the blind duodenal loop of a polyagastrectomy. The present case of villous adenoma in this situation therefore appears to be unique, in addition it presented special diagnostic difficulties and raises an interesting question in oncology.

\section{Case report}

In October 1970, a 71-year-old woman was admitted with tiredness of 7 years duration, more marked in recent months. She had been taking no medication during this period. On examination she was clinically anaemic, but there was no other 
abnormality. Previously, in 1949 a polyagastrectomy had been performed because of persistent pain from a duodenal ulcer. Investigations on admission showed a haemoglobin of $10 \mathrm{~g} / 100 \mathrm{ml}$, occult blood tests were repeatedly positive and sternal marrow showed normoblastic erythropoiesis with defective haemoglobinization and low iron stores.

Barium meal showed the gastric remnant to be normal; barium enema was normal. She was treated with intra-muscular iron and on discharge her haemoglobin was $12.5 \mathrm{~g} / 100 \mathrm{ml}$. In January, 1971, the patient was re-admitted with recurrence of the anaemia. Investigations at this time showed a haemoglobin of $8.7 \mathrm{~g} / 100 \mathrm{ml}$. Occult blood tests were again positive; sigmoidoscopy was normal. A repeat barium meal was also normal.

After blood transfusion a laparotomy was performed. No anastomotic ulcer was found. The small and large bowel were normal on external inspection; blood was seen in the terminal ileum.

The patient was admitted again in June, 1971, with further recurrence of anaemia. Investigations showed a haemoblobin of $7 \cdot 7 \mathrm{~g} / 100 \mathrm{ml}$. By injecting ${ }^{51} \mathrm{Cr}$-labelled red blood cells with four units of blood and measuring radio-activity of the faeces over the subsequent 7 days, it was shown that there was intermittent bleeding from the gastrointestinal tract, the daily blood loss varying from less than $1 \mathrm{ml}$ to $15 \mathrm{mls}$. After transfusion the haemoglobin rose to $10.2 \mathrm{~g} /$ $100 \mathrm{ml}$, then fell to $6.8 \mathrm{~g} / 100 \mathrm{ml}$ within 10 days. After further blood transfusion a second laparotomy was undertaken. A gastrotomy was performed and no abnormality was found. There was a small, soft mass palpable in the second part of the duodenum $2.5 \mathrm{~cm}$ distal to the duodenal stump. On opening the duodenum a soft papilliferous neoplasm was found and seen to be bleeding. The ampulla of Vater was not involved by tumour tissue and the neoplasm was excised locally. Careful inspection of the rest of the small bowel revealed no other lesion.

On the day after the operation the patient collapsed and died.

Post-mortem examination showed mesenteric infarction due to mesenteric artery thrombosis.

\section{Pathology}

The specimen was a pedunculated papillary mass $3 \times 2 \times 1.5 \mathrm{~cm}$ (Fig. 1). Microscopically it was a villous adenoma fundamentally no different from those seen in the large intestine (Figs. 2 and 3). There was no ulceration and no evidence of invasion at the base; the surrounding mucosa showed inflammatory changes. In view of its rarity, sections were sent to Dr B. C. Morson, who concurred with the diagnosis and adopted the tumour for the World Health Organization Reference Centre.

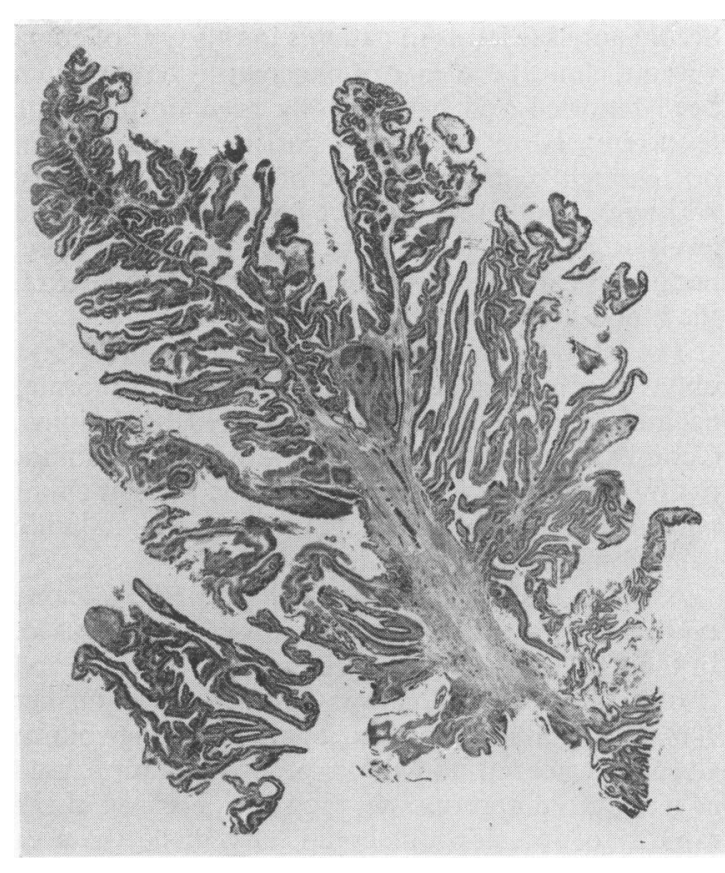

FIG. 1. Photomicrograph of cross section of tumour $\frac{\sigma}{\bar{\sigma}}$ ( $H$ and $E, \times 5 \cdot 8)$.

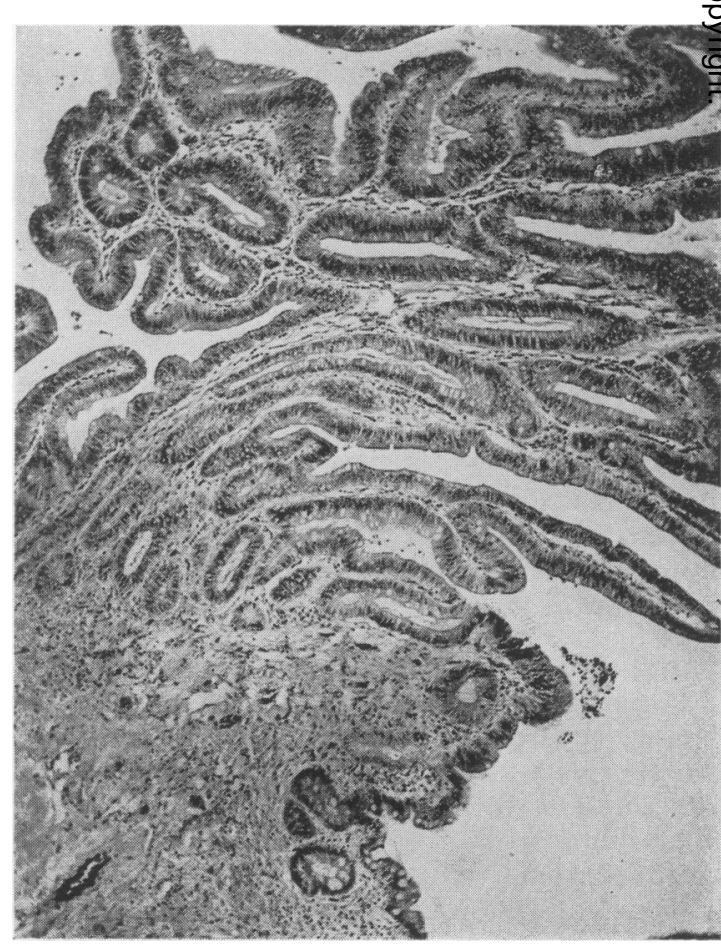

FIG. 2. Photomicrograph of villous adenoma ( $H$ and E, $\times 39)$. 


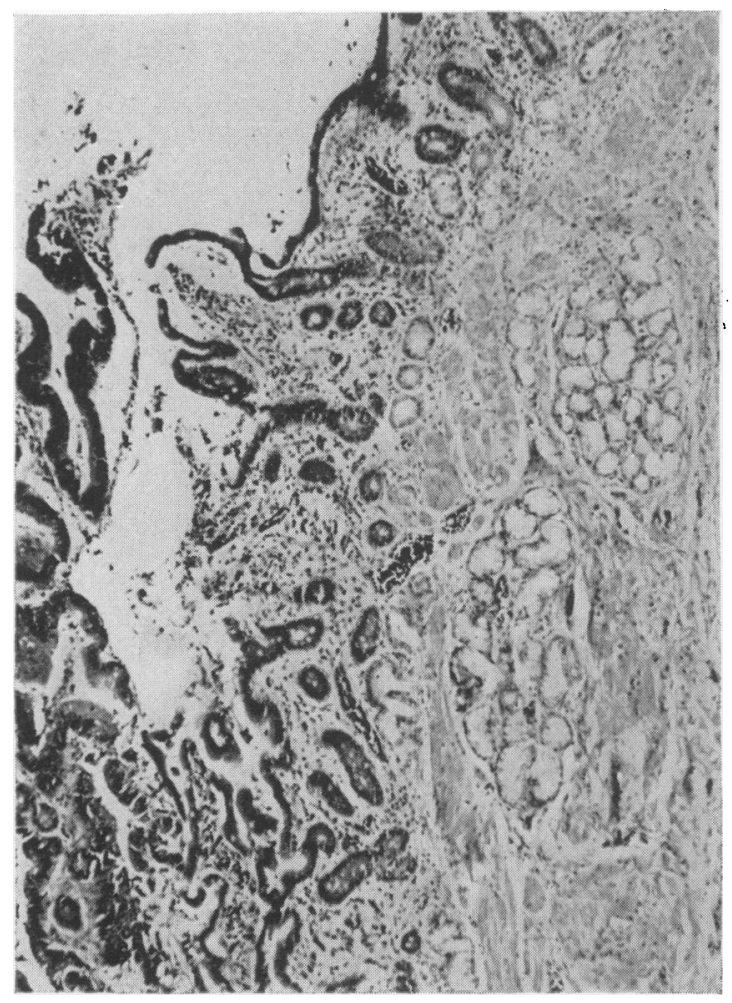

FIG. 3. Photomicrograph showing edge of tumour with adjacent duodenal mucosa ( $\mathrm{H}$ and $\mathrm{E}, \times 36$ ).

\section{Comment}

This patient presented as a case of recurrent gastrointestinal bleeding. Moersch, Wollner \& Clagett (1962) stated that this was a rare mode of presentation of a duodenal villous tumour, but three of the eleven cases previously reported presented in this way. Walk (1951) found that $75 \%$ of villous tumours of the large bowel bled significantly. Of the other patients with villous tumours of the duodenum, two presented with jaundice due to involvement of the common bile duct (Meltzer, Ostrum \& Isard, 1966), two with duodenal obstruction (Dwyer \& O'Brien, 1970; Hancock, 1970), and three with epigastric discomfort atypical of ulcer pain (Boyer \& Helfrich, 1966; Moersch et al., 1962; Noon, 1951). One patient had no symptoms referable to the tumour (Hoffman \& Grayzel, 1945).

Hoffman \& Grayzel (1945) noted in a series of fourteen cases that duodenal tumours tend to be asymptomatic, but only one villous adenoma was recorded. It is not known whether duodenal villous tumours have the same propensity to secrete mucus and electrolytes as do similar tumours in the large bowel, but absorption of the secretion would occur in the small bowel and the characteristic syndrome would therefore not appear.

In ten of the previous eleven cases the tumour was noted on barium meal examination, which is surprising, as adequate visualization of the duodenum using contrast media has only been possible since hypotonic duodenography was introduced a few years ago. When contrast media are used, Walk (1951) described a soap-bubble appearance, a 'mousse de savon' effect. This consisted of a tumour with multiple translucent areas interspersed with a fine lacework of radio opaque material which enters the clefts. Walk found an incidence of malignancy in $58 \%$ of villous tumours in the colon, and he also regarded a villous tumour of the stomach as a premalignant condition. He therefore condemned simple excision as being unjustified. Sunderland \& Binkley (1948) in examining such tumours pointed out that metastases are never seen if there is no local invasion outside the bowel, and so thought limited resection to be feasible. The feasibility of local resection is especially important in the duodenum, where the proximity of the common bile duct is a hazard. Malignant transformation in these villous tumours of the duodenum was usually accompanied by obstructive jaundice or obstruction of the intestinal contents, thus guiding the surgeon towards a more radical procedure.

Tumours developing in blind duodenal loops following gastrectomy are very rare, and this is only the third reported example. Two previous instances were a leiomyoma (Dawson, 1964) and a fibromyoma (Van Leberghe \& Henry, 1967). In Dawson's case gastrointestinal haemorrhage was not terminated by a gastrectomy done as a blind procedure. In Van Leberghe's case a polyagastrectomy was performed for a bleeding duodenal ulcer 8 years before the operation for the fibromyoma, which was associated with recurrent attacks of pancreatitis. The patient described in our report suffered from recurrent episodes of gastrointestinal bleeding 20 years after a polyagastrectomy for duodenal ulcer.

Recurrent bleeding is a difficult problem in a patient who has had a polyagastrectomy, and when one has excluded the usual causes such as anastomotic ulceration, unabsorbable suture material, or the development of a carcinoma in the remaining part of the stomach, the blind duodenal loop deserves thorough examination by duodenotomy.

Why neoplasms develop so rarely in blind duodenal loops is not known, but duodenal neoplasms are rare anyway. Primary epithelial neoplasms are rare throughout the small intestine, where both cell turnover and intestinal movement is rapid, but they are common in the large intestine, where the reverse applies. Interestingly, $30 \%$ of carcinomas developing in Crohn's disease of the small intestine occur in 
blind loops (Goldman et al., 1970), and recently Gleeson (1971) has shown that there is in rats slower cell turnover in Thiry Vella loops of small intestine compared to normal small intestine. Perhaps primary epithelial neoplasms should be more common in blind loops of duodenum than in normal duodenum. The extreme rarity of such tumours in such loops suggests that this is not the case.

\section{Acknowledgments}

We would like to thank Dr P. Markman for permission to publish this case, and we are grateful to Dr W. K. Blenkisopp and Dr B. C. Morson for the pathology reports.

\section{References}

Boyer, C.W. \& Helfrich, R.B. (1966) Adenoma of the duodenal bulb. American Journal of Roentology, 90, 753.

Bremer, E.H., Battaile, W.G. \& Bulle, P.H. (1968) Villous tumours of upper gastro-intestinal tract. American Journal of Gastroenterology, 50, 135.

DAwson, J.L. (1964) Leiomyoma of duodenum causing recurrent bleeding. Gut, 5, 184.

DWYER, W.A. \& O'BRIEN, R.F. (1970) Duodenal obstruction due to malignant villous adenoma. Transactions of the Medical Society of the State of New Jersey, 67, 477.

Gleeson, M. (1971) Personal communication.
Goldman, L.I., Barkow, S.P., Cox, W. \& Peale, A.R. (1970) Adenocarcinoma of small bowel complicating Crohn's disease. Cancer, 26, 1119.

HANCOCK, R.J. (1970) Eleven years review of primary tumours $C$ of small bowel and duodenum. Canadian Medical Association Journal, 103, 1177.

Hoffman, B.P. \& Grayzel, D.M. (1945) Benign tumours of duodenum. American Journal of Surgery, 70, 394.

Holmes, T. (1861) Villous tumours of the rectum. Transactions of the Pathological Society of London, 12, 120.

MAKKar, J., TAEK SONG, K. \& Cogbill, C.A. (1969) Villous adenoma of the duodenum. American Surgeon, 35, 656.

Meltzer, A.D., Ostrum, B.J. \& ISARD, H.J. (1966) Villous tumours of stomach and duodenum. Radiology, 87, 511.

MoersCh, R.N., Wollner, L.B. \& ClaGeTt, O.T. (1962) Villous adenoma of the duodenum. Surgery, 51, 574.

Noon, C. (1951) Adenoma of the duodenum. British Journal of Surgery, 39, 87.

SCHORSCH, H.A. \& GutierReZ, N. (1965) Villous adenoma of duodenum. American Journal of Gastroenterology, 44, 382.

Sunderland, D.A. \& Binkley, G.F. (1948) Papillary iv adenomas of large intestine and morphological study of $\mathrm{G}$ 48 cases. Cancer, 1, 84.

VAN Leberghe, R. \& HenRy, C. (1967) Un cas de tumeur of duodenale benigne chez un gastrectomise. Acta gastroenteriologica belgica, 30, 460.

WALK, L. (1951) Villous tumours of the stomach. Archives of Internal Medicine, 87, 560.

\title{
Liposarcoma of the kidney
}

\author{
W. M. LIEN* \\ M.B., Ch.B., F.R.C.S. \\ Dudley Road Hospital, Dudley Road, Birmingham B18 7QH
}

\section{Summary}

Two cases of liposarcoma of the kidneys were described, these being the thirty-sixth and thirty-seventh cases documented in the world literature. The association between renal liposarcoma and tuberous sclerosis was discussed. The presenting symptoms and signs of this condition were noted. A search of the recent world literature has been carried out.

\section{Introduction}

Although liposarcoma is the most common neoplasm of the retroperitoneum, it is a rare tumour in the kidney.

\section{Case reports}

Case 1

A female, aged 49 years, was admitted as an emergency to Dudley Road Hospital under the care

\footnotetext{
* Present address: General Hospital, Steelhouse Lane,
} Birmingham B4 6NH. of Mr A. O. Wilson on 4 July, 1972. $9 \mathrm{hr}$ prior to her admission, she suddenly developed a pain in the back, radiating towards the front and down the left side of her abdomen. There was no shoulder pain. She vomited five times. There were no abnormal: bowel or urinary symptoms.

On examination, the patient was in pain. Her pulse $\delta$ was 96 beats/min, regular. BP $150 / 110 \mathrm{mmHg}$. There was guarding and tenderness involving nearly the응 whole of the left half of her abdomen. The bowel

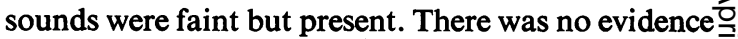
of peritonitis. There was a lower abdominal scar from a hysterectomy performed for uterine fibroids. in 1963.

Investigations. $\mathrm{Hb} 13.2 \mathrm{~g} / 100 \mathrm{ml}$; white cell count $14,500 / \mathrm{mm}^{3}$; electrolytes, liver function tests ando serum amylase were all normal. Straight $\mathrm{X}$-rays of the abdomen were normal. They showed no gas ${ }^{+}$ under the diaphragm and there was no evidence of ${ }^{\top}$ 